\title{
DERECHO PROCESAL CIVIL
}

Maite Aguirrézabal Grünstein

Profesora de Derecho Procesal

Universidad de Los Andes

Mediación PREVIa Obligatoria Y ACCESO A LA JUSTICIA EN EL PROCESO DE FAMILIA

\section{INTRODUCCIÓN}

En el presente trabajo se analiza la sentencia pronunciada por el TC con fecha 10 de julio de 2012, en la causa rol $\mathrm{N}^{\circ}$ 2042-11-INA, referida a la constitucionalidad del procedimiento de mediación como trámite previo y obligatorio para poder acceder a los tribunales de justicia.

La relevancia del fallo no es menor por cuanto que sin perjuicio que discurre en torno a la norma contenida en el artículo 43 de la ley $\mathrm{N}^{\mathrm{o}} 19.966$ sobre Régimen de Garantías de Salud, lo resuelto resulta plenamente aplicable a las normas que regulan la mediación en la ley $\mathrm{N}^{\mathrm{o}} 19.968$, que también establece un proceso previo y obligatorio de mediación.

Constituye, además, un fallo de gran interés puesto que permite el análisis de una institución que se ha ido incorporando en los nuevos procesos como una alternativa a la decisión jurisdiccional.
Especial importancia reviste por encontrarse actualmente en discusión el proyecto que reforma el proceso civil, y en que también se ha planteado el problema de la amplitud que debe reconocerse a los mecanismos alternativos de solución de conflictos, y su incorporación en carácter de previos u obligatorios.

\section{Hechos Relevantes QUE MOTIVAN EL FALLO}

En la causa sobre indemnización de perjuicios por negligencia médica, rol N 5195-2011, encontrándose la Corte Suprema conociendo de un recurso de casación en el fondo interpuesto por la demandante, $\mathrm{Pa}$ mela Bahamondes Moreno, interpone, además, un recurso solicitando se declare la inaplicabilidad por inconstitucionalidad de los incisos primero y segundo del artículo 43 de la ley $N^{0} 19.966$, que establece el régimen de garantías de salud, como consecuencia del recurso de casación interpuesto en contra de la sentencia de segunda instancia que confirma el fallo dictado por el $11^{\circ}$ Juzgado Civil 
de Santiago, que declara la nulidad de todo lo obrado en el proceso, por haberse omitido el trámite de mediación previa a la interposición de la demanda, establecida en el ya reseñado artículo 43.

Alega como fundamentos del recurso de inaplicabilidad, el que dicho artículo atenta contra las garantías constitucionales contenidas en el artículo $19 \mathrm{~N}^{\circ}$ 2, 3, 24 y 26, esto es, igualdad ante la ley, debido proceso, derecho de propiedad y afectación de los derechos en su esencia.

El TC, con fecha 5 de septiembre de 2011, declara admisible el requerimiento, para ser resuelto en el fallo que se comenta, de fecha 10 de julio de 2012, y en que se rechaza el recurso de inaplicabilidad interpuesto,
III. LA MEDIACIÓN COMO TRÁMITE PREVIO Y OBLIGATORIO EN LA LEY N ${ }^{\circ} 19.966$ Y EN EL PROCEDIMIENTO DE FAMILIA

$\mathrm{Al}$ igual que en materia de garantías en la salud, la ley $\mathrm{N}^{\circ} 19.968$ ha incorporado en su actual artículo 106 un proceso de mediación previo y obligatorio.

Dicha norma dispone:

"Las causas relativas al derecho de alimentos, cuidado personal $\mathrm{y}$ al derecho de los padres e hijos e hijas que vivan separados a mantener una relación directa y regular, aun cuando se deban tratar en el marco de una acción de divorcio o separación judicial, deberán someterse a un procedimiento de mediación previo a la interposición de la demanda, el que se regirá por las normas de esta ley y su reglamento".

Así, el razonamiento efectuado por el TC resulta pertinente a la hora de determinar si el proceso de mediación familiar se ajuste o no a los cánones constitucionales puesto que mucho se ha discutido sobre las ventajas y desventajas de establecer un proceso previo y obligatorio de este tipo en la legislación de familia.

La introducción de la mediación como proceso obligatorio en nuestra legislación se debe, principalmente, al colapso que sufrieron los tribunales de familia poco tiempo después de su entrada en vigencia y su imposibilidad de gestionar el alto número de demandas.

De ahí, entonces, que la ley $\mathrm{N}^{\mathrm{O}}$ 20.286, de 15 de septiembre de 2008, introdujo importantes reformas, entre las que se establece la mediación obligatoria, que ya se había encontrado contenida y luego desechada, en el proyecto original de la ley $\mathrm{N}^{\mathrm{O}}$ 19.968.

Así, se ordena la derivación obligatoria y previa a la interposición de la demanda, de todos aquellos asuntos relativos al derecho de alimentos, cuidado de los hijos y relación directa y regular ${ }^{1}$.

${ }^{1}$ Sobre las ventajas y desventajas de la mediación obligatoria, véase VARGAS (2008) pp. 183-202 y FiEgeLIST (2008) pp. 95-116. 
La ley $\mathrm{N}^{\mathrm{o}} 19.968$, en su artículo 103, define la mediación como

"aquel sistema de resolución de conflictos en el que un tercero imparcial sin poder decisorio, llamado mediador, ayuda a las partes a buscar por sí mismas una solución al conflicto y sus efectos, mediante acuerdos".

Su institucionalización obedece a la búsqueda de un objetivo definido: alcanzar acuerdos efectivos entre las partes y con un mayor alcance en el tiempo, protegiendo, además, a la parte más débil a través de un procedimiento más accesible y desformalizado, evitando con ello su judicialización, a la vez que se descongestiona el sistema judicial a través de la derivación de causas a mediación² .

\section{IV.- MEDIACIÓN PREVIA, DEBIDO PROCESO \\ Y ACCESO A LA JUSTICIA}

\section{Generalidades}

La protección de una situación jurídica debe desarrollarse en un plano sustantivo, pero también en un plano procesal. En el ámbito del Derecho Material se han realizado grandes progresos que no han venido acompañados de la creación de un sistema

\footnotetext{
${ }^{2}$ Idea que se refleja tanto en el mensaje del proyecto de las leyes $\mathrm{N}^{\mathrm{os}} 19.968,20.086$ y 19.966 .
}

de protección jurisdiccional que permita el ejercicio eficaz de algunos intereses ${ }^{3}$.

La preocupación por garantizar el acceso a la justicia a todas las personas no ha estado ausente de los procesos de reforma judicial. Dentro del conjunto de medidas dirigidas a corregir las condiciones de tiempo, modo o lugar que han limitado el acceso a la justicia, la lentitud de los procesos, el excesivo formalismo o su carácter excesivamente adversarial, se encuentran los mecanismos en la negociación, la conciliación, la mediación y el arbitraje como instrumentos complementarios de la justicia formal para la resolución de conflictos.

El acceso a la justicia como método de reforma del Derecho Procesal ha ido evolucionando en sucesivas "olas de reforma", identificándose tres etapas importantes:

1) La primera ola se concentra en los problemas que plantea la asistencia jurídica a los necesitados, proponiéndose sistemas que la provean y el beneficio de la justicia gratuita.

2) La segunda ola se relaciona con los problemas que plantea la defensa procesal de los intereses difusos y colectivos. Las reformas se refieren a la legitimación pro-

${ }^{3}$ Señalaba Couture (1989) p. 274, que "mientras el derecho material, por su parte, fue creando todo un sistema jurídico de excepción, el Derecho Procesal permaneció estacionario sobre las bases y fundamentos del sistema individualista". 
cesal activa de los organismos $\mathrm{y}$ asociaciones privadas y a otros derechos y mecanismos procesales. Las propuestas plantean un enfoque eminentemente público, que se manifiesta a través de la intervención del Ministerio Fiscal, las acciones populares o la institución del Defensor de los Consumidores, existente en Suecia, y cuya función consiste en representar los intereses fragmentados o difusos de los mismos. Los organismos internacionales han organizado diversas conferencias y adoptado muchos acuerdos que se reflejan en numerosos programas cada vez más especializados y complejos, y los ordenamientos jurídicos no se han quedado atrás en este sentido.

3) La tercera ola, conocida como "método de acceso a la justicia", incluye propuestas de reformas más globales que trastoquen el sistema procesal para asegurar la eficacia de los nuevos derechos surgidos en el Estado Social de Derecho.

A estas tres olas registradas hasta mediados de la década de 1980 , se suma una cuarta ola, dentro de la cual se han adoptado medidas para corregir problemas específicos de acceso a la justicia para remover barreras concretas ${ }^{4}$.

${ }^{4}$ Figuras tales como los jueces itinerantes -para garantizar el acceso a la justicia en

\section{Obstáculos en el acceso a la justicia}

Nos referiremos ahora a los obstáculos que alejan al justiciable de la justicia, que impiden su efectivo acceso a la misma, y que constituyen barreras o condicionamientos que atentan contra el principio de igualdad y el derecho a la tutela judicial efectiva. Asimismo, estas barreras se encuentran interrelacionadas, por lo que el problema tampoco se soluciona eliminándolas una a una.

Los obstáculos son numerosos, y pueden clasificarse en aquéllos que presentan un origen fáctico y aquéllos que son de carácter jurídico. En el campo del consumo obtienen demostraciones especialmente evidentes, puesto que el modelo tradicional de acceso al derecho a la tutela judicial y a obtener una resolución del litigio, caracterizado por su individualismo sólo ofrece a los consumidores una protección ficticia.

Una de las cuestiones más trascendentes se encuentra constituida por los elevados costos que supone un proceso, puesto que en esta ma-

lugares remotos; la administración judicial de los tiempos de un proceso-para garantizar un acceso a la justicia más expedito al permitir la reducción de los tiempos procesales de común acuerdo con las partes; la evaluación neutral previa del proceso - para restringir el litigio a los asuntos esenciales- o la provisión de asesores legales neutrales -para que sectores débiles o marginados de la población superen sus temores a negociar y sus desventajas frente a organizaciones privadas particularmente poderosas-, son algunos ejemplos de este tipo de medidas. 
teria los perjuicios sufridos por el particular suelen ser de pequeña cuantía, produciéndose, por tanto, una desproporción entre los gastos que genera un proceso ${ }^{5}$ y el monto de lo que puede reclamarse, lo que motiva la inactividad del afectado.

Para su superación, se han establecido incentivos de carácter pecuniario, como las normas de previsión de indemnizaciones superiores al perjuicio sufrido o la exoneración de las costas judiciales. Existe, también, el beneficio de la justicia gratuita, que se limita a los sectores más pobres de la sociedad. El ordenamiento español, en materia de protección de consumidores, concede a las asociaciones de los mismos este beneficio ${ }^{6}$.

También puede ser considerado como obstáculo de carácter económico la exigencia de cuantías mínimas para poder acceder a la justicia, que tiene como principal finalidad evitar un número excesivo de litigios ${ }^{7}$.

Como ya se señaló, los montos individuales que podrán reclamarse

${ }^{5}$ Entre los que se cuentan los honorarios profesionales de abogados, peritos, etcétera.

${ }^{6}$ Cfr. el artículo 20 de la ley 26/1984, de 19 de julio, para la defensa de los consumidores y usuarios, que dispone que las asociaciones de consumidores y usuarios disfrutarán del beneficio de justicia gratuita en los casos a que se refiere el artículo $2^{\circ} .2$, que, a su vez, dispone que los derechos de los consumidores y usuarios serán protegidos prioritariamente cuando tengan relación directa con productos o servicios de uso o consumo común, ordinario y generalizado.

${ }^{7}$ Con esta finalidad la directiva comunitaria 85/374/CEE, de 25 de julio de 1985, fija en su artículo 9 b) una cuantía mínima de 500 ECUS en lo relativo a daños materiales. serán generalmente exiguos, aunque considerados en su conjunto supongan una cantidad mucho más elevada. Parte de la doctrina propone como solución a esta barrera el permitir el acceso a los tribunales a las víctimas que reclamen de modo acumulado cuando superen en su conjunto la cuantía mínima exigida, tomando en consideración el monto global de los perjuicios y no los daños individualmente considerados ${ }^{8}$.

Los obstáculos de carácter cultural se refieren principalmente a la falta de educación e información de los ciudadanos acerca de sus derechos y obligaciones, la complejidad del lenguaje jurídico, etc. Junto a ellos se mencionan entre las barreras, la duración de los procesos, puesto que la justicia se torna inaccesible cuando resulta extremadamente lenta, ya sea por inactividad de las partes o por la falta de actuación del juez en su calidad de director del proceso.

Se señalan, asimismo, como un obstáculo las ventajas que pueden tener ciertas partes que poseen recursos económicos que les permiten sobrellevar los gastos que supone un juicio y que muchas veces se transforman en litigantes habituales, teniendo a su servicio toda una organización que les permite una mayor eficacia frente al litigante ocasional ${ }^{9}$.

${ }^{8}$ Cfr. Bercovitz (1987) pp. 282-283. En el mismo sentido, GutiérRez de Cabiedes (1999) p. 124.

${ }^{9}$ Términos acuñados por Galanter (1975) pp. 347 y 360, citado por CAPPELLETI y GarTh (1996) p. 19. 


\section{La mediación y los distintos mecanismos alternativos de solución de conflictos}

Parte importante de la doctrina sobre resolución de conflictos reconoce dos grandes sistemas de respuesta ${ }^{10}$.

El primero, denominado de autocomposición, integrado por aquellos medios en los cuales son las propias partes confrontadas las que resuelven sus desavenencias, en ejercicio de la autonomía de la voluntad, ya sea de manera directa o asistidos por terceros neutrales que facilitan el diálogo y la búsqueda de soluciones al conflicto. Dentro de este primer grupo se encuentran mecanismos como la negociación, la mediación y conciliación.

El segundo grupo, denominado 300 de heterocomposición, está compuesto por aquellos medios en los cuales las partes someten la solución de sus conflictos a terceros que se encargan de resolverlos independientemente de la de la voluntad de las partes. En este segundo grupo se ubican tanto los mecanismos de justicia formal como el arbitraje ${ }^{11}$.

La intervención de terceros neutrales dentro de estos dos sistemas

${ }^{10}$ Cfr. en este sentido, Singer (1994) Green y Sander (1985) Folberg y Taylor, (1992), Monroy (1997).

${ }^{11}$ Sin embargo, parte de la doctrina observa con preocupación la existencia de las cada vez más vías alternativas para la solución de los conflictos, puesto que han considerado que no deberían aplicarse en materias no disponibles por las partes, y que estos mecanismos no cuentan con las garantías que ofrece el proceso jurisdiccional. Véase en este sentido, Bordalí (2004) pp. 165-186. puede variar según el grado de su intervención y control del proceso, siendo más dispositiva o inquisitiva según el grado de control que las partes tengan sobre el proceso.

Se ha discutido en la doctrina si el derecho a acceder a la justicia cumple su finalidad con la sola consagración formal de recursos y procedimientos, o si se requiere también que éstos resulten realmente idóneos y eficaces. Así, la Corte Interamericana de Derechos Humanos ha sostenido:

“(...) la inexistencia de un recurso efectivo contra las violaciones a los derechos reconocidos por la Convención constituye una transgresión de la misma por el Estado Parte en el cual semejante situación tenga lugar. En ese sentido debe subrayarse que, para que tal recurso exista, no basta con que esté previsto por la Constitución o la ley o con que sea formalmente admisible, sino que se requiere que sea realmente idóneo para establecer si se ha incurrido en una violación a los derechos humanos y proveer lo necesario para remediarla" ${ }^{2}$.

En este mismo sentido se ha pronunciado al interpretar el artículo

12 Corte Interamericana de Derechos Humanos, Garantías Judiciales en Estados de Emergencia (arts. 27.2, 25 y 8, Convención Americana sobre Derechos Humanos), opinión consultiva OC-9/87 del 6 de octubre de 1987, serie A Nº. 9, párr. 24. 
25.1 de la Convención Americana de Derechos Civiles y Políticos para definir cuándo no existe recurso judicial efectivo, señalando:

“...no pueden considerarse efectivos aquellos recursos que, por las condiciones generales del país o incluso por las circunstancias particulares de un caso dado, resulten ilusorios. Ello puede ocurrir, por ejemplo, cuando su inutilidad haya quedado demostrada por la práctica, porque el Poder Judicial carezca de la independencia necesaria para decidir con imparcialidad o porque falten los medios para ejecutar sus decisiones; por cualquier otra situación que configure un cuadro de denegación de justicia, como sucede cuando se incurre en retardo injustificado en la decisión; o, por cualquier causa, no se permita al presunto lesionado el acceso al recurso judicial" ${ }^{13}$.

Así, y siguiendo los fallos citados, puede señalarse que para la Corte resulta claro que la justicia estatal

${ }^{13}$ Corte Interamericana de Derechos Humanos, Garantías judiciales en estados de emergencia (arts. 27.2, 25 y 8 Convención Americana sobre Derechos Humanos), opinión consultiva OC-9/87 del 6 de octubre de 1987, serie A No 9, párr. 24.). Esta opinión ha sido reiterada por la Corte Interamericana de Derechos Humanos, en los casos Velásquez Rodríguez, Fairén Garbi y Solís Corrales y Godínez Cruz. formal no siempre es efectiva, en especial cuando no se han previsto recursos judiciales idóneos y suficientes que faciliten la solución pacífica de los conflictos, o cuando la complejidad de los procedimientos o de las condiciones de tiempo, modo y lugar exigidas por el legislador restringen la capacidad de alcanzar el goce efectivo de los derechos cuya protección se busca al acudir a las instancias judiciales, y que

"los mecanismos alternativos de resolución de conflictos no representan una desconfianza hacia la justicia estatal formal, sino un reconocimiento de que procedimientos menos formales y alternativas de justicia autocompositiva complementan las opciones a las cuales pueden acudir las personas para resolver sus disputas. Por ello, mecanismos como la mediación y la conciliación, más que medios para la descongestión judicial, son instrumentos para garantizar el acceso efectivo a la justicia y promover la resolución pacífica de los conflictos" ${ }^{\prime 14}$.

Los mecanismos alternativos de solución de conflictos son una de las soluciones propuestas para la superación de los obstáculos antes descritos.

${ }^{14}$ Sentencia C-1195/01, de la Corte Constitucional de Colombia, disponible en www.corteconstitucional.gov.co/relatoria/2001/c-1195-01.htm. 
Entre los muy diversos problemas que demandan una solución jurídica y medios eficaces para resolver las controversias se encuentran, por ejemplo, la complejidad cada vez mayor de las relaciones jurídicas, y la necesidad de tratar con situaciones especialmente dinámicas, como consecuencia de nuevas tecnologías, nuevos campos de actividad y nuevas formas de hacer negocios, lo que muchas veces se traduce también en la búsqueda de soluciones urgentes que den respuesta oportuna en determinadas condiciones.

A lo anterior debe agregarse que la realidad parece mostrar órganos jurisdiccionales casi siempre saturados por el número de asuntos pendientes, y que por razones de especialización en ocasiones resultan poco idóneos para resolver ciertas controversias, en función de la complejidad o de la naturaleza de la situación jurídica planteada o de las partes que en ella intervienen.

Actualmente el debate está planteado en la oposición de la utilidad de los mecanismos jurisdiccionales para la resolución de todos los problemas de la ciudadanía en su conjunto o, bien, si es posible encontrar otras formas de hacerlo.

De ahí entonces que haya surgido la necesidad de plantearse el contar con procedimientos flexibles, que superen problemas inherentes a la jurisdicción ordinaria; de medios e instrumentos capaces de resolver las controversias en función de las características del objeto del proceso $\mathrm{y}$ de las partes que intervienen, con mayor celeridad y a un costo menor,

y que permitan llegar a soluciones funcionales y satisfactorias ${ }^{15}$.

La mediación es tal vez el más informal, expedito y económico de los mecanismos alternativos de solución de conflictos, y puede señalarse que forma parte de las actuales políticas encaminadas a promover el acceso a la justicia.

\section{Mediación previa obligatoria y acceso a la justicia}

a) La mediación como mecanismo de superación de los obstáculos en el acceso a la justicia

Cabe plantearse si la mediación de carácter previo atentaría contra la garantía constitucional establecida en el artículo $19 \mathrm{~N}^{\circ} 3$ de nuestra Constitución Política. Ello porque la obligatoriedad del procedimiento obstaculizaría el acceso al órgano jurisdiccional, derecho consagrado en el texto constitucional y que confiere a toda persona la posibilidad real de acceder igualitariamente a la justicia no siendo sus derechos limitados con exigencias de actuaciones prejudiciales.

El fallo se pronuncia sobre este punto en el considerando vigésimo noveno y siguientes, señalando que la igualdad en el ejercicio de los derechos supone, además, el derecho de acceso a la jurisdicción, sin impedimentos de ningún tipo que coarten ese derecho ${ }^{16}$.

${ }^{15}$ Así, la mediación es más dispositiva que la conciliación, porque el tercero (mediador) no actúa como amigable componedor.

${ }^{16}$ Ya se había pronunciado el TC, en este sentido, cuando en el considerando $\mathrm{N}^{\circ} 9$ de 
A pesar de lo anterior, sostiene el tribunal que no puede entenderse que la exigencia de una mediación previa obstaculice el libre acceso a la justicia, puesto que el proceso no impide que luego se pueda recurrir efectivamente a los tribunales de justicia en el evento que la mediación fracase.

Señala la sentencia, que debe tenerse presente que el acuerdo de mediación ha sido elevado a la categoría de equivalente jurisdiccional, es decir, resuelve un conflicto de carácter jurídico con efectos equivalentes a los que produce una sentencia y con efecto de cosa juzgada, lo que permitiría su cumplimiento forzado.

Así, el artículo 111 de la ley $\mathrm{N}^{\circ}$ 19.968 dispone que el acta de mediación

“deberá ser remitida por el mediador al tribunal para su aprobación en todo aquello que no fuere contrario a derecho, pudiendo el juez en todo caso subsanar los defectos formales que tuviera, respetando en todo momento la voluntad de las partes expresada en dicha acta. Aprobada por el juez, tendrá valor de sentencia ejecutoriada".

La sentencia pronunciada por el TC considera que no existe un aten-

la STC N² 25, señalaba: "toda persona tiene derecho a recurrir al juez en demanda de justicia, pues es la compensación por haberse prohibido la autotutela como solución para los conflictos". tado contra la igualdad ante la ley cuando se establece un proceso de este tipo de modo previo al ejercicio de acciones jurisdiccionales puesto que no existiría una diferencia arbitraria, y porque, paulatinamente, las reformas procesales han ido estableciendo sistemas alternativos de solución de conflictos, que permitirían

"acuerdos por una vía confiable, rápida, económica y ajustada a los cambios sociales, tecnológicos y económicos en curso..." $"$.

Agrega en los considerandos vigésimo quinto y vigésimo sexto que no se estima que exista razón para considerar que el procedimiento de mediación previa no es adecuado.

Además, considera el sentenciador que la diferencia que se efectúa en estos procedimientos es necesaria, puesto que el proceso de mediación resulta más accesible, simplificado y de más bajo costo que el procedimiento judicial ${ }^{18}$.

Se trataría, asimismo, de un procedimiento idóneo puesto que propende a que las partes logren la solución

${ }^{17}$ Orden de servicio $\mathrm{N}^{\circ} 1$, de 20 de enero de 2002, Dirección del Trabajo.

${ }^{18} \mathrm{El} \mathrm{TC}$, en diversos fallos, ha señalado que la prohibición de discriminación arbitraria es una dimensión de la igualdad que no significa que toda diferencia exija un trato legal diferenciado, pues ello haría imposible establecer reglas generales. Lo que la Constitución prohíbe no es hacer diferencias, sino hacer diferencias arbitrarias". Considerando $\mathrm{N}^{\circ} 22$ de la STC rol N 807, de 4 de octubre de 2007. 
extrajudicial de una controversia, pero con los efectos propios de una transacción.

Es decir, el acuerdo alcanzado en la mediación alcanza la categoría de equivalente jurisdiccional $\mathrm{y}$, por lo tanto, produce los efectos propios de la cosa juzgada, lo que resulta determinante al momento de lograr el cumplimiento del acuerdo alcanzado.

Se señala en la sentencia que la mediación no impide el acceso a la justicia, puesto que de fracasar este proceso previo, siempre podrá recurrirse al órgano jurisdiccional para alcanzar la solución del conflicto mediante una sentencia judicial.

Para los detractores de este tipo de soluciones alternativas al proceso, en especial cuando tienen el 304 carácter de previas y obligatorias, no tiene fundamento pretender que la mediación pueda sustituir la jurisdicción ordinaria de manera absoluta e indefinida en el tiempo, bajo el pretexto de obtener una definición pronta del conflicto.

Destacan que lo que debe primar en la gestión de estos mecanismos es la voluntad de las partes, que debe estar presente en la libertad de iniciativa de someterse al proceso, y en la actividad orientada a solicitar la participación de un tercero ajeno al aparato de la justicia para que dirima determinada controversia ${ }^{19}$.

${ }^{19}$ Así, se ha señalado: "La voluntad de conciliar es una sola y comprende, ontológicamente, la decisión de optar por ella. Por ello en esta materia no es admisible establecer una dicotomía entre la conciliación como procedimiento y la conciliación como
Interesante en este punto resulta el voto de minoría emitido por los ministros Hernán Vodanovic, Enrique Navarro e Iván Aróstica, quienes estuvieron por acoger la inaplicabilidad solicitada por cuanto consideran que el trámite de la mediación previa y obligatoria sí atenta contra el derecho contenido en el artículo $19 \mathrm{~N}^{\circ} 3 \mathrm{de}$ nuestra Constitución.

Señalan en este sentido, que infringiría el precepto constitucional una mediación obligatoria que constituya un presupuesto para el libre acceso a la justicia, puesto que se trata de un procedimiento que tiene lugar fuera del Poder Judicial vulnerando con ello también el artículo 76 de la Constitución, que dispone expresamente:

"la facultad de conocer, juzgar
y hacer ejecutar lo juzgado

posibilidad de disponer de un derecho subjetivo, a fin de sostener que en el primer caso el legislador puede imponerla como requisito de procedibilidad, en tanto y en cuanto desde esa óptica tiene un sentido meramente instrumental o mediático", agregando: "Así pues, ha de concluirse que dada la naturaleza facultativa de los mecanismos alternativos de solución de conflictos, el legislador no puede establecer la conciliación como requisito obligatorio de procedibilidad para acudir ante la jurisdicción, porque al hacerlo está desconociendo el núcleo esencial del derecho de acceder a la administración de justicia, del cual también forma parte la decisión libre y espontánea de los asociados de escoger la vía adecuada -judicial o extrajudicial-, para la solución de sus controversias. Sentencia C-1195/01, de la Corte Constitucional de Colombia, disponible en www.corteconstitucional.gov. co/relatoria/2001/c-1195-01.htm. 
corresponde exclusivamente a los tribunales de justicia"

Así, el voto disidente se manifiesta en contra del objetivo que persiguen las reformas procesales para "evitar la judicialización injustificada y excesiva" y "propender a que las partes lleguen a un acuerdo extrajudicial", lo que, en definitiva, implica que cierto tipo de asuntos que hasta ahora han sido de naturaleza litigiosa y conocidos directamente por los tribunales, pierdan esa calidad mediante la introducción forzada de un proceso desarrollado ya sea en ámbitos privados o administrativos, y en los que se llega a una solución extrajudicial que produce los efectos de una transacción,

"todo lo cual supone, obviamente, predisponer al afectado a que decline algunas de sus reclamaciones y haga ciertas concesiones" $" 20$.

Además, el artículo $19 \mathrm{~N}^{\circ} 3$ asegura el acceso a la jurisdicción sin trabas, garantizado el derecho al juez natural, es decir, el ser juzgado por un el órgano jurisdiccional que corresponde en aplicación de las normas de competencia, y que haya sido previamente establecido por la ley ${ }^{21}$.

${ }^{20} \mathrm{~N}^{\circ} 2$ del voto disidente de la STC de fecha 10 de julio de 2012.

${ }^{21}$ Idea consagrada en las STC rol $\mathrm{N}^{\circ}$ 792, 946, 1386, entre otras. Agregan PalOMO y VALenZuela (2012) p. 402: "la igualdad en el ejercicio de los derechos supone el derecho a acceder a la jurisdicción para satisfacer
Por último, si la Constitución garantiza a todas las personas igual protección de la ley en el ejercicio de sus derechos, esta protección comienza, necesariamente, por la garantía de acceder a los órganos encargados de la protección de los derechos.

En consecuencia, debe entenderse que el artículo 19 número 3 de la Constitución Política asegura a toda persona el derecho a acceder a los órganos jurisdiccionales ${ }^{22}$.

De modo reiterado el mismo tribunal constitucional ha señalado también que el acceso a la justicia es una garantía insustituible e irremplazable porque de ella depende la protección real de los derechos ${ }^{23}$.

Considera el voto de minoría que:

"asumir a priori que la sola interposición de unas acciones reparatorias puede generar alguna judicialización injustificada y excesiva, aparte de configurar una predicción sin fundamento, no puede justificar que al sospechado se lo induzca a despreciar un derecho claro e incuestionable, porque en tal caso no se le estaría

la pretensión que sustenta un justiciable. Desde ese punto de vista, la satisfacción de esa pretensión a través del proceso no debe experimentar impedimentos u obstáculos que, en definitiva, coarten el acceso a la justicia".

${ }^{22} \mathrm{STC}$ rol N $\mathrm{N}^{\circ} 792$, de 3 de enero de 2008.

${ }^{23}$ Así, en las STC 792 de fecha 3 de enero de 2008, 968 de fecha 10 de julio de 2008, ha confirmado este criterio de exclusividad de la jurisdicción para el conocimiento de asuntos de carácter contencioso. 
asegurando la constitucionalmente debida protección de la ley en el ejercicio de sus derechos" ${ }^{\prime 24}$.

En opinión de este voto, para evitar que mecanismos alternativos forzados de solución de conflictos sólo podrían tener lugar bajo el alero del Poder Judicial puesto que constitucionalmente sólo a éstos les corresponde resolver de modo exclusivo todos los asuntos contenciosos de cualquier naturaleza e independiente de la calidad de las personas que intervengan en el litigio.

De ahí que un proceso de mediación como el que actualmente contempla el proceso de familia podría representar un obstáculo para acceder a la justicia, y que, además, se trata de una diligencia que se realiza fuera del ámbito judicial, lo que podría provocar un problema de injerencia en las funciones del Poder Judicial, afectando con ello su independencia, consagrada constitucionalmente.

En esta misma línea de pensamiento, destacan Diego Palomo Vélez y Williams Valenzuela Villalobos señalan:

"los disidentes ponen de manifiesto una serie de inconstitucionalidades que adolece la norma, la más importante a nuestro juicio, es aquella que vulnera abiertamente el derecho a la igual protección

${ }^{24} \mathrm{~N}^{\circ} 4$ del voto disidente de la STC de fecha 10 de julio de 2012 . de la ley en el ejercicio de los derechos, con expreso reconocimiento en el numeral $3^{\circ}$ del artículo 19 de nuestra Carta Fundamental. En consecuencia, no se pueden establecer mecanismos que inhiban a la jurisdicción estatal de conocer y resolver determinados conflictos" ${ }^{\prime 2}$.

Se ha señalado que el proceso de mediación tal como está ahora regulado en la ley $\mathrm{N}^{\circ} 19.968$, no ha arrojado tampoco los resultados esperados ${ }^{26}$.

Así, el sistema mixto de prestación del servicio de mediación arroja una serie de problemas, tales como los incentivos por los acuerdos alcanzados en los distintos procesos de mediación, la desinformación de los usuarios del servicio o el conflicto entre mediación gratuita y pagada, pues de no calificar el justiciable para el sistema de mediadores licitados en atención a sus ingresos, necesariamente deberá costear un mediador privado, lo que podría observarse como un obstáculo claro en el acceso a la justicia ${ }^{27}$.

${ }^{25}$ Palomo y Valenzuela (2012) p. 410.

${ }^{26}$ Sobre este punto en particular, las estadísticas en materia de mediación están disponibles en los distintos informes preparados al respecto por el Ministerio de Justicia.

${ }^{27}$ Sobre este aspecto en particular, $\mathrm{PA}^{-}$ REDES (2012) p. 203, señala: "en ocasiones se ha destacado el supuesto bajo costo de la mediación como sistema general, pero no es posible desconocer los mecanismos jurídicos y administrativos existentes en los Estados, así como también en nuestro sistema jurídico, 


\section{Conclusiones}

1) El derecho de acceso a la justicia es una garantía consagrada constitucionalmente que permite a los justiciables recurrir para la solución de sus conflictos a órganos jurisdiccionales que se caracterizan por su independencia e imparcialidad.

2) Ante los numerosos obstáculos que parece plantear en la realidad el acceso a la justicia, la búsqueda de mecanismos alternativos de solución de conflictos se ha transformado en un tema de relevancia y actualidad.

3) La mediación surge como un procedimiento alternativo, desformalizado y de menor costo que el proceso judicial, que busca soluciones más efectivas en el tiempo, con alcance de equivalente jurisdiccional, estableciéndose de modo previo y obligatorio para descongestionar los tribunales de justicia.

4) El fallo del TC en su mayoría considera que el establecimiento de sistemas alternativos obligatorios y previos al acceso al órgano jurisdiccional no atentarían contra el debido proceso y la igualdad ante la ley sino que, además, beneficiarían el acceso del ciudadano a la justicia.

encaminados a garantizar la atención y servicios jurídicos gratuitos a quienes no pueden proveérselos por sí mismos. Lo que se complementa en el antecedente que recurrir al tribunal, o someter a la decisión de un juez un tema controvertido no tiene costo para la parte".
5) Sin perjuicio de lo señalado en el numeral anterior y de este criterio mayoritario, creemos que no debe perderse de vista que procedimientos de este tipo presentan en nuestra legislación varias debilidades que deben ser superadas para alcanzar un verdadero resultado práctico.

6) Debe considerarse que se trata de mecanismos ajenos al Poder Judicial, por lo que las garantías de legalidad, independencia e imparcialidad como requisitos mínimos de cualquier debido proceso, son de muy difícil control. Por ello, su aplicación debe ser acotada y para materias muy específicas.

7) Además, creemos que, de una u otra forma, suponen una postergación en el ejercicio del derecho consagrado en el artículo $19 \mathrm{n}^{\circ} 3$ de nuestra Carta Fundamental y ello debe ser siempre considerado como un obstáculo más.

\section{Bibliografía CITADA}

Bercovitz Rodríguez-Cano, Rodrigo (1987). "La responsabilidad de los fabricantes en la Directiva de las Comunidades Europeas de 25 de julio de 1985". En Alberto Bercovitz Rodríguez-CANo, Estudios jurídicos sobre protección de los consumidores. Madrid: Tecnos.

Bordalí Salamanca, Andrés (2004). "Justicia Privada". Revista de Derecho de la Universidad Austral de Chile, vol. xvi. Valdivia, julio. 
Couture, Eduardo (1989). Estudios de Derecho procesal civil. Buenos Aires: Depalma.

Fiegelist Venturelli, Rodrigo (2008). "La mediación previa y obligatoria en los tribunales de familia establecida por la ley 20.086. Un análisis comparativo". Revista de Derecho de la Universidad de Concepción. año LXXVI, $\mathrm{N}^{\circ}$ 223-224. Concepción, diciembre.

Folberg, Jay, Alison Taylor (1992). Mediación: resolución de conflictos sin litigio. México: Limusa.

Galanter, Marc (1996). "Afterward: Explaining Litigation". Law \& Soc Rev., 1975, pp. 347 y 360, citado por Mauro CAPPELLETI y Bryant GaRTH. El acceso a la justicia. La tendencia en el movimiento mundial para hacer efectivos los derechos. México: Fondo de la Cultura Económica.

308
Monroy Cabra, Marco Gerardo (1997). Métodos alternativos de solución de conflictos. Oxford: University Press.

Palomo Vélez, Diego, Williams Valenzuela Villalobos (2012). "Descarte de la incosntitucionalidad de la obligatoriedad de la mediación prejudicial que establece la ley $\mathrm{N}^{\circ} 19.966$ : lectura crítica de la sentencia del Tribunal Constitucional", Ius et Praxis, año $18, \mathrm{~N}^{\circ} 2$, Talca.

Paredes Zieballe, Alejandro (2012). "La mediación familiar obligatoria: una crítica a la regulación y funcionamiento en Chile". Revista Chilena de Derecho y Ciencia Política. vol. $3 \mathrm{~N}^{\circ} 2$, Temuco, agosto-diciembre.

Singer, Linda (1990). Settling Disputes: Conflict Resolution in Business, Families, and the Legal System. Boulder: Westview Press.

Vargas Pavez, Macarena (2008). "Mediación obligatoria. Algunas razones para justificar su incorporación”. Revista de Derecho de la Universidad Austral de Chile, vol. Xxi. No 2, Valdivia, diciembre. supraindividuales: colectivos y difusos. Pamplona: Aranzadi. 